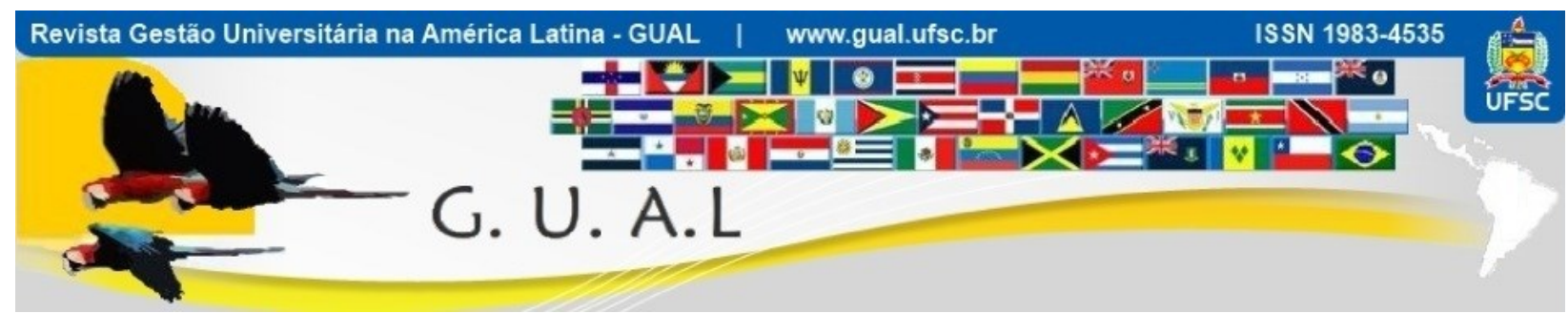

DOI: http://dx.doi.org/10.5007/1983-4535.2016v9n2p1

\title{
INFLUÊNCIA DA ESTRUTURA ORGANIZACIONAL- ADMINISTRATIVA DAS INSTITUIÇÕES DE ENSINO SUPERIOR NO DESENVOLVIMENTO DE COMPETÉNCIAS DOCENTES PARA ATUAÇÃO NA EAD
}

\begin{abstract}
INFLUENCE OF ORGANIZATIONAL AND ADMINISTRATIVE STRUCTURE OF HIGHER EDUCATION INSTITUTIONS IN THE DEVELOPMENT OF TEACHING SKILLS TO OPERATE IN EAD
\end{abstract}

Fernanda Roda de Souza Araújo Cassundé, Doutora Universidade Federal do Vale do São Francisco - UNIVASF fernanda.roda@univasf.edu.br

José Ricardo Costa Mendonça, Doutor Universidade Federal de Pernambuco - UFPE jrcm@ufpe.br

Milka Alves Correia Barbosa, Doutora Universidade Federal de Alagoas - UFAL milka.correia@gmail.com

Recebido em 18/outubro/2014

Aprovado em 08/fevereiro/2016

Sistema de Avaliação: Double Blind Review Esta obra está sob uma Licença Creative Commons Atribuição-Uso. 


\title{
RESUMO
}

A performance dos indivíduos que atuam na educação a distância é influenciada por diversos fatores, porém a dimensão organizacional-administrativa da instituição de ensino se constitui um elemento fundamental para o desenvolvimento das competências eletrônicas docentes, haja vista que tanto deve reforçar as habilidades quanto promover a conquista de novas aptidões que lhes permitam conhecer e julgar por que, quando e como utilizar as TICs na EAD. Partindo dessa premissa, esse estudo procura responder a seguinte pergunta: Como o desenvolvimento das competências eletrônicas dos professores do ensino superior se relacionam com a dimensão organizacional-administrativa das instituições de ensino superior? Para tanto, foi realizado um qualitativo interpretativo básico. Foi escolhido como lócus a Universidade Federal do Vale do São Francisco e, como unidade de análise, o curso de especialização em Gestão Pública vinculado ao Programa Nacional de Administração Pública (PNAP). A coleta de dados foi realizada mediante pesquisa documental e entrevistas com roteiro semiestruturado. Os resultados da pesquisa mostram claramente que vários fatores dessa dimensão são importantes para o desenvolvimento das competências eletrônicas docentes e que questões políticas institucionais precisam ser superadas e a periodicidade do treinamento precisa existir para que a EAD possa se firmar na instituição.

Palavras-chave: Condições institucionais. Integração das TICs. Competências eletrônicas. Educação a distância. Ensino superior.

\begin{abstract}
The performance of individuals working in distance education is influenced by several factors, but the organizational and administrative dimension of the educational institution is a key element for the development of e-skills teachers, given that both should reinforce skills as promoting conquest of new skills to enable them to know and judge for what, when and how to use ICTs in distance education. From this premise, this study seeks to answer the following question: As the development of electronic skills of teachers in higher education are related to organizational and administrative dimension of higher education institutions? Thus, a basic interpretive qualitative was conducted. Was chosen as the locus Federal University of Vale do São Francisco and as a unit of analysis, the specialization course in Public Management linked to the National Program of Public Administration (PNAP). Data collection was conducted through desk research and interviews with semi-structured. The survey results clearly show that several factors of this dimension are important for the development of electronic teaching skills and institutional policy issues need to be overcome and the frequency of training needs exist for distance education can be established in the institution.
\end{abstract}

Keywords: Institutional conditions. Integration of ICTs. Electronic skills. Distance education. Higher education. 


\section{INFLUÊNCIA DA ESTRUTURA ORGANIZACIONAL-ADMINISTRATIVA DAS INSTITUIÇÕES DE ENSINO SUPERIOR NO DESENVOLVIMENTO DE COMPETÊNCIAS DOCENTES PARA ATUAÇÃO NA

\section{INTRODUÇÃO}

Em virtude dos inúmeros apelos socioeconômicos e tecnológicos do sistema educacional, as instituições de ensino superior brasileiras têm sido motivadas a interiorizar, a dinamizar e a aprimorar a forma de gerar e transmitir o conhecimento. Assim, atendendo a uma determinação prevista na Constituição Federal de 1988, desde 2002, vem ocorrendo um processo de interiorização dos cursos superiores no país.

A educação a distância aparece, então, "como uma modalidade de educação extremamente adequada e desejável para atender às novas demandas educacionais decorrentes das mudanças na nova ordem econômica mundial” (BELLONI, 2009, p.3). Por isso é que a criação de Centros de Educação a Distância tem sido processo comum das instituições educacionais nos últimos anos no sentido de viabilizar tanto o ensino de graduação quanto o de pós-graduação no país, bem como o investimento de recursos substanciais para explorar os potenciais do ensino a distância na educação superior (Schönwald, 2003).

$\mathrm{O}$ apoio que a EAD tem recebido da tecnologia, cujos instrumentos passaram a dinamizar todo o processo de ensino-aprendizagem e a tornar mais próximo o "contato" por intermédio do mundo virtual, tem mudado gradualmente o ensino superior e feito com que as instituições de ensino enfrentem a complexa tarefa de integrar a tecnologia ao contexto tradicional dos cursos (SCHNECKENBERG, 2004; 2008a; Wheeler, 2010). Na medida em que as potencialidades são viabilizadas com apoio das TICs, inúmeras atividades têm sido permitidas com a EAD, impactando, sobremaneira, tanto as instituições de ensino superior brasileiras quanto a docência. Assim, o processo de passagem de um modelo de educação presencial para outro, a distância, envolve mudanças organizacionais, culturais, de equipamentos, de posicionamento institucional, de modelos de gestão, de processos de aprendizagem e, sobretudo, de competências e atividades dos professores (ISMAN; ALTINAY; ALTINAY, 2004; ARRUDA, 2007; MARTINS, 2008; RAMA, 2008; ZANOTELLI, 2009; GILBERTO, 2013).

Em função dessas exigências, qualquer perspectiva de melhoria ou inovação na educação exige uma melhor capacitação dos formadores. Ou seja, essa perspectiva está ligada por uma dependência a um corpo docente altamente qualificado e atento às necessidades específicas de vários aprendizes, e que é capaz de implementar estratégias bem sucedidas para o processo de ensino-aprendizagem. Para isso, é primordial o desenvolvimento de 
determinadas competências específicas (Ehlers; Schneckenberg, 2010; UMAR; DANAHER, 2010), denominadas eletrônicas ou e-competências.

Esse tipo de competência é baseada na motivação e capacidade dos docentes em utilizar TICs, ou seja, faz referência à habilidade no uso das TICs no dia a dia da prática educacional, seja ela em nível individual ou coletivo (SCHNECKENBERG; WILDT, 2006; SCHNECKENBERG, 2007, 2010b). É, no entanto, uma das competências mais difíceis de serem desenvolvidas no contexto atual do ensino porque diz respeito à cultura técnica e à capacidade de integrar materiais pedagógicos em suportes tecnológicos mais sofisticados. Se, por um lado, é possível perceber que as TICs já fazem parte do cotidiano da maioria das crianças e adolescentes, por outro lado, diversas pesquisas em âmbito internacional, como, por exemplo, Chen (2008), Sánchez-Franco; Martínez-López; Martín-Velicia (2009), Oguzor; Opara (2011) e Lwoga (2012) demonstram a dificuldade da integração dessas TICs na prática diária do professor, tendo em vista a utilização desses recursos para favorecer o processo de ensino-aprendizagem.

Nesse sentido, apesar de as políticas públicas para a expansão e de o desenvolvimento da EAD serem realidade para maioria das IES do país e existir consenso entre docentes e gestores de que é preciso avançar nessa modalidade de ensino para além de práticas isoladas, percebe-se ainda, em muitas delas, a falta de uma abordagem de mudança da gestão universitária para a integração das TICs ao processo de ensino-aprendizagem da EAD, mostrando que tal modalidade de ensino ainda não é compatível com as estruturas e valores atualmente existentes nas universidades (Schönwald, 2003; Schneckenberg, 2008b).

Nesse sentido, Seufert e Euler (2003) identificaram cinco dimensões essenciais para a implementação eficiente da EAD em contextos universitários, quais sejam:

1. Dimensão econômica, representada pela eficiência e efetividade no uso dos recursos;

2. Dimensão técnica/tecnológica, representada pela estabilidade e funcionalidade adequados da infraestrutura técnica;

3. Dimensão organizacional-administrativa, representada pela capacidade de adaptação e eficiência das estruturas e processos para implementação da EAD;

4. Dimensão sociocultural, representada pela mudança de cultura para um novo processo de ensino-aprendizagem; e

5. Dimensão pedagógico-didática, representada pelo desenvolvimento de novas competências em função de novos ambientes de ensino-aprendizagem e meios de comunicação. 
Essas cinco dimensões representam as condições institucionais necessárias para respaldar o desenvolvimento das competências eletrônicas dos professores do ensino superior de modo a permitir a integração das TICs ao processo ensino-aprendizagem.

Assim, entendendo que o corpo docente desempenha um papel decisivo na estratégia de uma universidade para melhorar e ampliar os seus serviços educacionais com a ajuda da tecnologia (SCHNECKENBERG, 2007; VOLK; KELLER, 2010; GILBERTO, 2013), entende-se que uma universidade só tem condições de orientar e implementar tecnologias orientadas para inovação no processo de ensino-aprendizagem em EAD se:

a) os membros (docentes) estão conscientes sobre a necessidade de adaptar a cultura de trabalho ao ambiente em mudança;

b) os ambientes de aprendizagem da EAD estiverem alicerçados em uma infraestrutura diferente daquela que é utilizada na modalidade presencial;

c) os membros fazem o uso insistente do potencial da TIC; e, sobretudo,

d) o desenvolvimento das competências necessárias para os membros tiver respaldo em condições dadas pelos contextos organizacionais (favoráveis à EAD) previamente institucionalizados (dimensões para implementação da EAD em contextos universitários).

Este estudo é, portanto, orientado pela seguinte questão que se coloca entre o problema e o campo de investigação: Como o desenvolvimento das competências eletrônicas dos professores do ensino superior, que propiciam a integração das tecnologias de informação e comunicação ao processo ensino-aprendizagem na educação a distância, relacionam-se com a dimensão organizacional-administrativa das instituições de ensino superior?

\section{SOBRE AS COMPETÊNCIAS ELETRÔNICAS}

Diversos são os autores que apontam que o trabalho docente no ensino superior exige o desenvolvimento de competências específicas em harmonia aos projetos individuais, institucionais e sociais (MENEZES, 2001; RAMOS, 2002; PAIVA, 2007; MENDONÇA et al, 2012b). Tais competências, do ponto de vista de Beraza (2006), devem ser constituídas por conhecimentos (conteúdos a serem ensinados, processos de ensino-aprendizagem), por habilidades específicas (comunicação, didática, métodos, processos avaliativos) e por um conjunto de atitudes próprias dos docentes enquanto formadores (disponibilidade, empatia, rigor intelectual, ética profissional, entre outras características). Corroborando com esse entendimento, Tigellar et al (2004, p.255, grifo nosso) complementam que as competências 
para o ensino podem ser definidas como "um conjunto integrado de características pessoais, conhecimentos, habilidades e atitudes, que são necessários para a efetiva performance em variados contextos de ensino".

Dessa feita, quando a profissão do professor passa a ser compreendida enquanto práticas associadas ao ato de ensinar, adquire características específicas (e distintas) de quaisquer outras atividades e/ou funções desempenhadas pelos professores do ensino superior, demandando, portanto, competências próprias e diferenciadas para tal (BERAZA, 2006; GILBERTO, 2013).

Ao se considerar, entretanto, o novo contexto educacional estabelecido pelo avanço tecnológico, pelo estímulo ao uso das TICs e pela consolidação da EAD, "acredita-se ser de fundamental importância a consideração de competências tecnológicas no exercício da profissão docente" (MENDONÇA et al, 2012a, p.7).

Assim, os professores, além de reforçarem as competências que já possuem, precisam, também adquirir novas competências que lhes permitam conhecer e julgar por que, quando e como utilizar as TIC na educação (SCHNECKENBERG, 2010b; VOLK; KELLER, 2010). Isso porque a EAD em muito difere no tempo e espaço da tradicional educação presencial, e o professor passa a ser um mediador no acesso à informação durante o processo de ensinoaprendizagem, exigindo desse profissional novas competências, uma vez que ele precisa ser sensibilizado e preparado para utilizar todo o potencial educativo das tecnologias disponíveis para a EAD e, assim, provavelmente, novos saberes vão sendo construídos (HARRY; DESMOND; JONH, 2006; ARRUDA, 2007; MARTINS, 2008; SANAVRIA, 2008; SOUZA; SARTORI; ROESLER, 2008; JAKOBSDÓTTIR; MCKEOWN; HOVEN, 2010; VOLK; KELLER, 2010; GILBERTO, 2013). Paiva (2007) acrescenta que os avanços tecnológicos afetam diretamente o professor, permanecendo como um ponto questionável de sua atividade, uma vez que a revolução tecnológica está produzindo 'a fórceps' uma nova profissionalidade docente.

Quando inseridos na EAD, os professores têm que ser capazes de reconhecer as limitações e o potencial da tecnologia, bem como as melhores técnicas para a comunicação por meio dessa tecnologia, reformulando práticas pedagógicas de modo a possibilitar a criação de novas experiências (SOUZA; SARTORI; ROESLER, 2008; TORRES; MARRIOT; MATOS, 2009; VOLK; KELLER, 2010; MOORE; KEARSLEY, 2011), e para 
isso, novas competências precisam ser desenvolvidas, pois o docente na EAD desempenha papéis de outras complexidades.

Uma análise dos referenciais de qualidade para cursos de ensino superior a distância do MEC (BRASIL, 2007) sinalizam indicadores que permitem a compreensão das particularidades na formação do professor que atua em cursos a distância. As competências eletrônicas, portanto, não incluem apenas os aspectos técnicos, mas também a visão mais ampliada sobre a capacidade educativa para a utilização das TIC no ensino e aprendizagem (SCHNECKENBERG, 2010b; VOLK; KELLER, 2010; GILBERTO, 2013).

O fato é que o ensino na modalidade a distância é um desafio para a maioria dos docentes, exemplificam Moore e Kearsley (2011), especialmente por esse ser intermediado por uma tecnologia, permeando as práticas pedagógicas na EAD. Mesmo que os professores do ensino superior não tenham passado por um treinamento formal para exercer a regência na modalidade presencial, a maioria consegue moldar seu comportamento em sala de aula com base nos professores que teve enquanto foi aluno. Porém, até recentemente, dificilmente, uma "pessoa havia tido experiência ou recebido treinamento sobre como ensinar usando a tecnologia. As pessoas que se tornam instrutores na EAD [...] precisam aprender, desempenhando as funções com quase nenhuma orientação" (p.147), ou seja, os professores, geralmente, deparam-se com situações não vivenciadas anteriormente enquanto aluno, uma vez que a maioria se formou no ensino presencial (SOUZA; SARTORI; ROESLER, 2008; GILBERTO, 2013). Outros autores (Schneckenberg, 2008a; LATCHEN, 2010) também corroboram essa ideia ao afirmarem que são poucos os cursos que preparam os professores para a $\mathrm{EAD}$, especialmente no que se refere às questões pedagógicas associadas às TICs. $\mathrm{O}$ que se percebe, portanto, muitas vezes, é uma formação inadequada dos professores justamente para integração das TICs aos processos de ensino.

O professor, quando entra em contato com a EAD, como caracterizam Souza, Sartori e Roesler (2008, p.329),

passa a se confrontar tempos e espaços organizados de uma forma diferente; estabelece um contato com os alunos sem contar com os olhares e gestos e, em várias situações, sem ter uma reação imediata sobre o que foi apresentado e proposto. Estes elementos implicam em um conjunto de saberes didáticopedagógicos 'novos', que, em muitos casos, colocam em xeque encaminhamentos dados para situações presenciais. 
Essas circunstâncias reforçam, portanto, a necessidade do desenvolvimento de competências específicas (LATCHEN, 2010), as chamadas competências eletrônicas, para o docente atuar na EAD, pois essa modalidade tem proporcionado modelos de ensino inovadores e cada vez mais vem ganhando espaço em cursos de graduação e pós-graduação no país.

\section{SOBRE A DIMENSÃO ORGANIZACIONAL-ADMINISTRATIVA}

No que se refere à IES, Euler e Seufert (2003) apresentam um modelo teórico para a mudança de gestão de universitária com o qual argumentam que a instituição de ensino superior precisa desenvolver uma abordagem estratégica que identifique e agregue valor de elearning às suas atividades centrais, que atenda aos seus contextos específicos e suas condições. As condições institucionais que podem viabilizar a implementação da EAD em contextos universitários estão apresentadas na figura 1 a seguir.

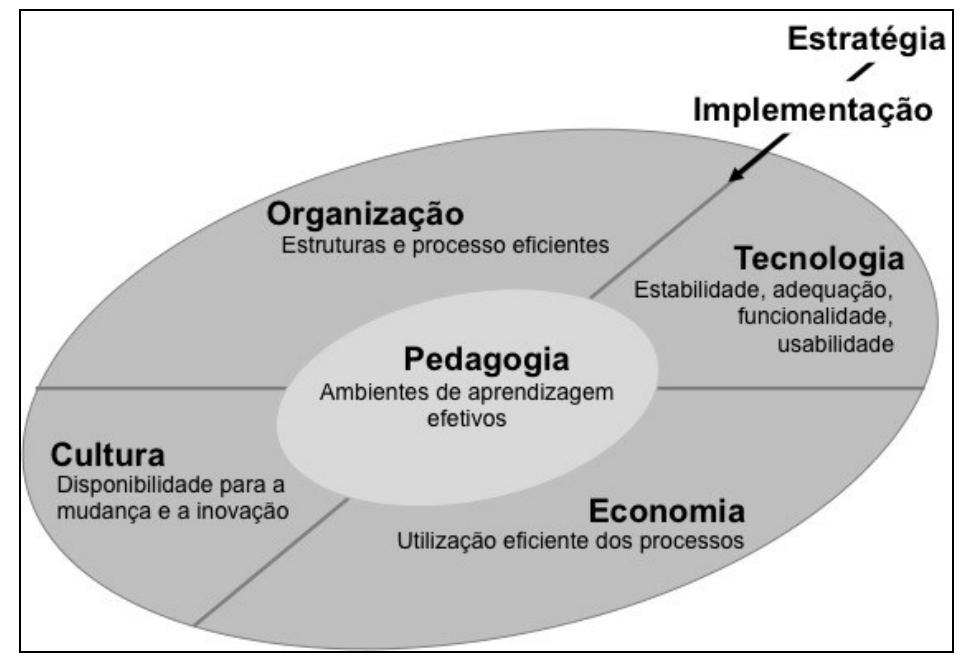

Figura 1 Dimensões para a implementação da EAD em contextos universitários. Fonte: Adaptado de Seufert e Euler (2003).

Schönwald (2003) afirma que essas cinco dimensões ligadas às condições institucionais formam a estrutura necessária para o processo de mudança e institucionalização da EAD nas universidades, e que elas exercem influência umas nas outras. Seufert e Euler $(2003$; 2004) fizeram um detalhamento sobre tais dimensões, a saber:

O principal objetivo da dimensão organizacional-administrativa é garantir a capacidade de adaptação e a estabilidade das estruturas e processos a fim ancorar institucionalmente a EAD em um ambiente organizacional favorável para sua implementação. 


\section{INFLUÊNCIA DA ESTRUTURA ORGANIZACIONAL-ADMINISTRATIVA DAS INSTITUIÇÕES DE ENSINO SUPERIOR NO DESENVOLVIMENTO DE COMPETÊNCIAS DOCENTES PARA ATUAÇÃO NA $E A D$ \\ DOI: http://dx.doi.org/10.5007/1983-4535.2016v9n2p1}

Um planejamento que contemple toda a universidade e o estabelecimento de uma estratégia de implementação da EAD é, portanto, um fator chave para garantir a viabilidade dessa modalidade de ensino. É também importante a gestão das partes interessadas, levando em consideração as necessidades dos diferentes atores envolvidos (professores, alunos e técnicos) nesse processo quando do uso (ou suporte) da infraestrutura tecnológica disponível. Com o propósito de aumentar a flexibilidade e adaptabilidade da instituição de ensino superior, é preciso desenvolver uma gestão de qualidade em toda a universidade para fazer, por exemplo, processos de mudança organizacional transparentes. Nesse sentido, a estratégia de implementação deve também considerar a avaliação das atividades de EAD, a fim de verificar a melhoria da qualidade do ensino universitário a partir da perspectiva das principais partes interessadas e, com base nos resultados da avaliação, planejar e implementar novas (quando necessário) atividades de EAD.

Assim, a análise das cinco dimensões apresentadas fornece um ponto de partida fundamental para identificar e avaliar as condições institucionais e, sobretudo, analisar de que maneira (tais dimensões) impactam no desenvolvimento de competências eletrônicas dos professores para integrar as tecnologias de informação e comunicação aos processos de ensino.

\section{METODOLOGIA}

Este estudo, em função de suas características, foi desenvolvido considerando-se a abordagem qualitativa tanto para coleta quanto análise dos dados. Assim, enquanto estratégia de pesquisa qualitativa, optou-se pelo estudo qualitativo interpretativo básico ou genérico, como frequentemente é apresentado na literatura (Merriam, 1998; 2002). Esse tipo de estudo, conforme descrevem Merriam (1998; 2002), Caelli, Ray e Mill (2003); Godoy (2005) e Stake (2005), exemplifica todas as características da pesquisa qualitativa, pois o pesquisador está interessado em compreender como os sujeitos dão sentido a uma situação ou fenômeno.

Foi escolhido como lócus a Universidade Federal do Vale do São Francisco e, como unidade de análise, o curso de especialização em Gestão Pública vinculado ao Programa Nacional de Administração Pública (PNAP). É importante salientar que a escolha por essa IFES (Instituição Federal de Ensino Superior) considerou o critério de acessibilidade dos pesquisadores, do impacto regional, local e nacional, bem como a participação no Projeto PróADM - Capacitação Docente para EAD, financiado pela CAPES em edital específico. 


\section{INFLUÊNCIA DA ESTRUTURA ORGANIZACIONAL-ADMINISTRATIVA DAS INSTITUIÇÕES DE ENSINO SUPERIOR NO DESENVOLVIMENTO DE COMPETÊNCIAS DOCENTES PARA ATUAÇÃO NA $E A D$ \\ DOI: http://dx.doi.org/10.5007/1983-4535.2016v9n2p1}

A área de Administração foi a escolhida em função de seu destaque na atuação em atividades de EAD (CASSUNDÉ; CASSUNDÉ JUNIOR, 2012; PADILHA; HELAL; MENDONÇA, 2012), inclusive sendo o curso piloto de graduação em Administração responsável por inaugurar, efetivamente, a UAB em 2006 (SILVA et al, 2012).

Neste estudo, a coleta de dados foi realizada mediante pesquisa documental e entrevistas com roteiro semiestruturado. Essas duas técnicas de coleta de dados configuram-se as principais fontes de dados para uma pesquisa qualitativa de acordo com Merriam (2002). A escolha por múltiplas fontes de dados segue as orientações de Godoy (1995), Bauer, Gaskell e Allum (2002) e Vieira (2004), quando salientam que, ao ir a campo, o pesquisador deve considerar diversos tipos de dados que precisam ser coletados e analisados para que seja possível compreender a dinâmica do objeto em estudo.

Considerando que a pesquisa qualitativa busca entender o significado de um fenômeno a partir das perspectivas de seus sujeitos e que a "representatividade não é um princípio de seleção de dados" (BAUER; AARTS, 2002, p.54), torna-se importante selecionar casos ricos em informação para o estudo em profundidade, ou seja, aqueles casos a partir dos quais se pode aprender muito sobre questões de fundamental importância para o objetivo da pesquisa, caracterizando, portanto, uma seleção intencional ou proposital (MERRIAM, 2002).

Assim, para determinar o corpus de análise, Merriam (2002) sugere que é necessário inicialmente estabelecer os critérios essenciais na escolha de quem deve ser entrevistado. $\mathrm{O}$ quadro 1, a seguir, apresenta os critérios definidos para este estudo e, consequentemente, a definição dos sujeitos, considerando o lócus e o objeto de estudo.

\begin{tabular}{|l|l|l|}
\hline \multicolumn{2}{|c|}{ Critério de seleção } & \multicolumn{2}{|c|}{ Características } & \multicolumn{2}{c|}{ Sujeitos } \\
\hline $\begin{array}{l}\text { Atores inseridos na prática } \\
\text { educacional }\end{array}$ & $\begin{array}{l}\text { Atores que vivenciam a prática } \\
\text { docente a partir das condições } \\
\text { impostas pela instituição. }\end{array}$ & $\begin{array}{l}\text { Nacional vinculados ao de Formação em } \\
\text { Administração Pública no curso de } \\
\text { Gestão Pública. }\end{array}$ \\
\hline
\end{tabular}

Quadro 1 Definição de critérios para seleção do corpus.

Fonte: Elaborado pelos autores (2015).

Os sujeitos que compuseram o grupo de respondentes foram os servidores da universidade e que estavam vinculados, à época, ao Programa Nacional de Formação em Administração Pública no curso de Gestão Pública. O grupo de respondentes, a quantidade prevista (total de sujeitos) de entrevistas e a quantidade de entrevistas realizadas estão apresentados na tabela 1. 
Tabela 1 Grupo de entrevistados.

\begin{tabular}{lcc}
\hline Perfil do Entrevistado & Quantidade prevista & Entrevistas realizadas \\
\hline Coordenadores & 03 & 03 \\
Professores & 11 & 08 \\
TOTAL & 14 & 11 \\
\hline
\end{tabular}

Fonte: Elaborado pelos autores (2015).

A fim de garantir a confidencialidade dos respondentes, foram atribuídos códigos de referência para identificá-los durante a transcrição de suas falas na análise de dados. O critério de julgamento para o encerramento da coleta de dados deste estudo foi o da saturação teórica que, de acordo com Bauer e Aarts (2002) e Godoi e Mattos (2006), sugere rigor ao processo de pesquisa qualitativa.

Considerando os objetivos e as técnicas de coleta de dados propostos neste estudo, entende-se que o procedimento mais adequado para a análise dos dados é a Análise de Conteúdo. Nesse sentido, este estudo utilizou a Análise Categorial, que é uma das técnicas mais utilizadas e conhecidas da Análise de Conteúdo proposta por Bardin (2011) e que, nos últimos anos, vem se destacando entre os métodos qualitativos de análise, ganhando legitimidade e sendo amplamente reconhecida no campo da produção científica em Administração (Mozatto; Grzybovski, 2011).

Com o propósito de garantir maior confiabilidade à análise e proceder a uma interpretação mais qualitativa, na qual o pesquisador prende-se às nuanças de sentido que existem entre as unidades, foi utilizada a estratégia de análise de emparelhamento. Essa estratégia pressupõe a associação dos dados recolhidos a um modelo teórico, possibilitando a comparação, ou seja, essa estratégia supõe a presença de uma teoria forte na qual o pesquisador se fundamenta para imaginar um modelo de fenômeno ou da situação investigada.

Considerando a legitimidade e a crescente utilização de softwares como apoio para análise do material empírico em pesquisas qualitativas (BANDEIRA-DE-MELLO, 2006; MAIETTA, 2008), o software ATLAS.ti ofereceu suporte a esta etapa da pesquisa.

\section{ANÁLISE DE DADOS E DISCUSSÃO DOS RESULTADOS}

O objetivo central da dimensão organizacional/administrativa refere-se à capacidade de adaptação e eficiência das estruturas e processos de modo que permita o estabelecimento de uma âncora institucional para o desenvolvimento da EAD em um ambiente organizacional 
favorável para sua implementação, definem Seufert e Euler (2003). O planejamento da implementação da EAD na universidade é, para os autores, um fator crucial para o desenvolvimento de competências eletrônicas dos professores e atuação na EAD pelas instituições, uma vez que irá permitir uma aceitação maior da modalidade do ensino a distância. Assim, é preciso repensar a EAD como parte de conceitos estratégicos mais amplos relacionados à inovação educacional (SCHNECKENBERG, 2010a).

$\mathrm{Na}$ análise documental, percebe-se, claramente, portanto, um planejamento da instituição em relação aos avanços da EAD. O Plano de Desenvolvimento Institucional (PDI) elaborado para o período de 2009 a 2014 ainda sob a gestão do antigo reitor, Prof. Dr. José Weber Freire Macedo, por sua vez, compreendido como um plano de apoio à gestão e que considera as particularidades da instituição para o estabelecimento dos objetivos e metas estratégicas, representou um momento único da vida institucional da UNIVASF que, pela primeira vez depois de sua criação, no ano de dois mil e dois, e após os seus primeiros cinco anos de funcionamento acadêmico, extrapola os seus limites formais construindo cenários e indicadores que representam o amadurecimento da sua comunidade docente, discente, técnico-administrativo e bem como da sua relação com a sociedade civil.

O que se pode verificar na análise do PDI é que, em várias passagens do texto, há a previsão ao estímulo e impulso da EAD na instituição, quais sejam:

- Criação de cursos na modalidade a distância (uma das metas estabelecidas para o período);

- Possibilitar o uso de $20 \%$ da carga horária das disciplinas presenciais para atividades de ensino a distância (como forma de flexibilizar a gestão das disciplinas);

- Implementar uma rede local de ensino superior a distância, com exigente padrão de qualidade, após a capacitação do seu corpo docente (propostas para o ensino de graduação); e,

- Assegurar aumento significativo da oferta de vagas por meio de da implantação de novos cursos em nível de graduação e pós-graduação, nas modalidades de ensino presencial e de ensino a distância (implantação e desenvolvimento de curso).

As ações e propostas estabelecidas no PDI para a educação a distância na UNIVASF para o período compreendido no documento analisado estão demonstradas na teia de relacionamentos da figura a seguir. 


\section{INFLUÊNCIA DA ESTRUTURA ORGANIZACIONAL-ADMINISTRATIVA DAS INSTITUIÇÕES DE ENSINO SUPERIOR NO DESENVOLVIMENTO DE COMPETÊNCIAS DOCENTES PARA ATUAÇÃO NA $E A D$ \\ DOI: http://dx.doi.org/10.5007/1983-4535.2016v9n2p1}

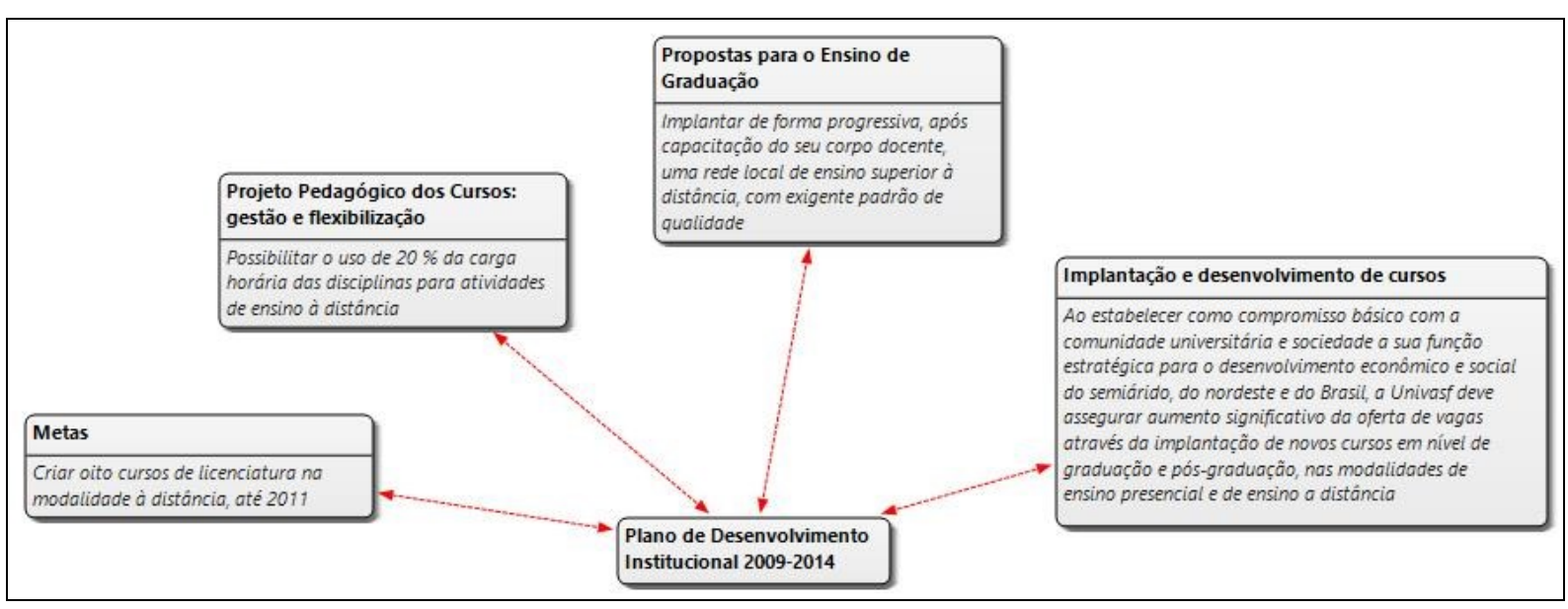

Figura 2 Teia para as ações/propostas para a educação a distância no Plano de Desenvolvimento Institucional para o período 2009-2014 da UNIVASF.

Fonte: UNIVASF, 2009b.

Em razão de o PDI prever a capacitação do corpo docente para implementar uma rede local de ensino superior a distância, questionou-se aos professores se eles haviam tido um treinamento prévio oferecido pela UNIVASF, mais especificamente a Secretaria de Educação a Distância (SEaD), uma vez que o principal objetivo das condições institucionais para o desenvolvimento de competências docentes é, para Schneckenberg (2010a), apoiar o professor no processo de aprendizagem.

Embora os professores entrevistados tenham sugerido que o treinamento oferecido foi basicamente para apresentação do ambiente virtual de aprendizagem utilizado pela instituição, o moodle, e desenvolvimento de aptidões básicas na plataforma, eles reconhecem que o treinamento foi bastante importante, considerando o fato de que muitos deles não conheciam o AVA adotado. Trechos das entrevistas refletem esse cenário.

Então a gente aprendeu como se lança uma atividade, como se lança um fórum, como desenvolve todo um roteiro de ministrar uma disciplina.

Ent_UNIVASF_2

(...) para poder utilizar o ambiente moodle. Para podermos operar o sistema sem grandes dificuldades. Eu vou confessar que me ajudou bastante.

Ent_UNIVASF_4

(...) mas só das competências técnicas, só de uso da plataforma. Nada sobre didática, só o básico mesmo.

Ent_UNIVASF_7

Nós tivemos um curso que ensinou a mexer na plataforma, o moodle. Deu para sair conhecendo a ferramenta, as funções, as possibilidades. Então, sob este aspecto, a ferramenta não foi algo que dificultasse.

Ent_UNIVASF_8 


\section{INFLUÊNCIA DA ESTRUTURA ORGANIZACIONAL-ADMINISTRATIVA DAS INSTITUIÇÕES DE ENSINO SUPERIOR NO DESENVOLVIMENTO DE COMPETÊNCIAS DOCENTES PARA ATUAÇÃO NA $E A D$ \\ DOI: http://dx.doi.org/10.5007/1983-4535.2016v9n2p1}

Os professores também reconhecem que, embora exista o treinamento básico, ele não é capaz de atender à demanda existente na Universidade como um todo. Esse treinamento ocorreu quando da criação e estruturação da SEaD. À época, fora uma aposta de um determinado professor da Universidade, que trabalhava junto a Pró-Reitoria de Ensino (PROEN), que estimulou o uso e, para tal, resolveu oferecer os treinamentos iniciais e formar multiplicadores. Os multiplicadores, por sua vez, ministravam os treinamentos e formavam um banco de cadastro, para quando a $\mathrm{SEaD}$ começasse a oferecer os cursos. Esse cenário encontrado na UNIVASF é previsto por Moore e Kearsley (2011) como sendo muito comum em instituições que resolvem utilizar a modalidade de ensino a distância. Os autores destacam que a orientação e o treinamento frequentemente se originam de pessoas que sabem um pouco mais do que as outras, mas os instrutores (professores, tutores) geralmente precisam descobrir sozinhos as limitações e o potencial da tecnologia, como também as melhores técnicas para comunicação por meio dessa tecnologia. É comum, ainda que, no caso da educação superior, "a maioria dos professores não tenha passado por um treinamento formal" para o uso da tecnologia (MOORE; KEARSLEY, 2011, p.147).

Assim, em virtude da pouca ou nenhuma experiência e conhecimento, a demanda pelo curso foi maior do que a oferta de vagas, e sem pessoal capacitado para oferecer o treinamento, acabou deixando de existir. Atualmente, para os novos professores (e, porventura, novos tutores) não é oferecido treinamento algum sobre a plataforma.

Seguem os trechos da entrevista.

O Prof. Gama ${ }^{1}$ promovia um curso [...]. Lançavam os editais internos, as turmas iam se formando e faziam o curso. Foi assim que a EAD surgiu em minha vida.

Ent_UNIVASF_6

(...) o moodle foi mais uma aposta do Prof. Gama, na época ele trabalhava junto a PROEN, ouviu falar e bancou, ele aprendeu, ele desenvolveu, instalou e incentivou o uso. E eu fui um dos primeiros adotantes desse sistema. [...] As primeiras instruções, que eram bem informais, eram dadas pelo Prof. Gama

Ent_UNIVASF_7

(...) quando a $\mathrm{SEaD}$ começou a ser estruturada, foram dados alguns cursos iniciais para se trabalhar com ambiente virtual de aprendizagem, no nosso caso, o moodle. As primeiras turmas geraram alguns multiplicadores, e eu fui um desses multiplicadores, cheguei a dar alguns cursos. E a gente começou àquela época preparar um banco de cadastro de tutores porque a gente tinha ideia de que a coisa ia começar e precisava desse pessoal preparado. Para você ter uma ideia, eu recebi tutores sem ter recebido capacitação para a plataforma. Ou seja, a demanda foi maior

\footnotetext{
${ }^{1} \mathrm{O}$ nome verdadeiro do professor foi omitido em função de não ter sido solicitada a permissão para utilizá-lo, sendo necessário, portanto, confidencialidade. Assim, neste estudo, chamaremos este docente de Prof. Gama.
} 


\section{INFLUÊNCIA DA ESTRUTURA ORGANIZACIONAL-ADMINISTRATIVA DAS INSTITUIÇÕES DE ENSINO SUPERIOR NO DESENVOLVIMENTO DE COMPETÊNCIAS DOCENTES PARA ATUAÇÃO NA $E A D$ \\ DOI: http://dx.doi.org/10.5007/1983-4535.2016v9n2p1}

e não existiam pessoas capacitadas para isso. Existe, por exemplo, no momento, uma turma para capacitar e requalificar de 60 pessoas, eu tenho tutor que trabalha comigo que ficou de fora, que não conseguiu vaga, então existe, a capacitação existe, mas ela não é suficiente. A demanda, a quantidade de pessoas para se capacitar ainda é muito maior do que o que está sendo oferecido.

Ent UNIVASF 10

Apenas os entrevistados Ent_UNIVASF_3 e Ent_UNIVASF_5 disseram não ter participado de treinamento prévio oferecido pela instituição. Para o Ent_UNIVASF_3, nenhum tipo de treinamento foi oferecido, embora ele tenha solicitado pessoalmente a SEaD. $\mathrm{O}$ que este entrevistado levou de experiência para a EAD foram as práticas docentes que adotava para as aulas presenciais, como a utilização de AVAs, a exemplo do Universia. Quando a UNIVASF aderiu ao moodle transpôs seu material para esse novo ambiente. Embora tenha dito que não participou de nenhum treinamento, tal professor reconhece que esse é oferecido pela instituição.

O treinamento que eu acho que a universidade dá é insuficiente, que o treinamento que a universidade dá é você utilizar o moodle. É aprender sobre a plataforma.

Ent_UNIVASF_3

Assim, entende-se que o professor não participou do curso não pela inexistência do mesmo, mas, por entender que, como já sabia previamente operar uma ferramenta, não estava disposto a fazer um treinamento para essa finalidade. Esperava algo mais.

(...) o curso está todo voltado para a plataforma. E não é só isso. É muita coisa.

Ent_UNIVASF_3

Já o professor Ent_UNIVASF_5, também reconhece a oferta do treinamento pela instituição; não entanto, não participou desse porque já conhecia a plataforma e, por ser um curso apenas de noções básicas, acreditava que já tinha conhecimentos suficientes.

Então eu sei que teve. Não participei porque eu tinha o conhecimento.

Ent_UNIVASF_5

Não há unanimidade com relação à legitimação da EAD na UNIVASF. Parte dos professores acredita já ser legitimada em virtude do próprio meio em que alunos, professores e técnicos administrativos estão inseridos e vivenciando as atividades de EAD na instituição. No entanto, também relacionam essa aceitação a questões políticas, quais sejam: mudança de gestão da universidade e as políticas públicas existentes que, por meio do esforço do Poder Público nos últimos anos, há um incentivo para o desenvolvimento de programas na área educacional e muito especificamente da educação a distância para as instituições públicas de 
ensino superior. E, ainda, reconhecem que quem não conhece a EAD marginaliza esta modalidade de ensino.

De grande parte ainda sim. Quem não conhece, marginaliza. Mas quem conhece, acredita que o ensino a distância deva ocorrer dentro da universidade.

Ent_UNIVASF_2

Sinto que atualmente sim, já conseguem ter certa legitimação, mas seria melhor se não tivessem tantos elementos políticos que permeiam ainda esse ambiente da EAD.

Ent_UNIVASF_5

$\mathrm{Na}$ Univasf eu não vejo resistência dos professores, e os eventuais críticos, participam, pelo fato financeiro. Se fosse grátis ou partisse das nossas atribuições obrigatórias, eles seriam contra, seriam resistentes. Outro aspecto que poderia ser político, ideológico está sendo suprimido, que é o fato de receber bolsa. Cala a boca da dissonância cognitiva.

Ent_UNIVASF_7

Para aqueles professores que não reconhecem a legitimação da EAD na UNIVASF, a principal questão atribuída é o fato de a comunidade acadêmica acreditar que a EAD é inferior ou sem qualidade quando comparada ao ensino presencial, e, por isso, existe um preconceito geral em torno dessa modalidade de ensino, especialmente para aqueles em que a tecnologia não faz parte do cotidiano, que apresentam certa resistência ao uso de recursos tecnológicos. A própria instituição não reconhece a carga horária do docente quando ele atua na EAD. Para efeitos de computação de carga horária, apenas são contabilizadas as horas trabalhadas na educação presencial. Aqueles que trabalham na EAD não têm sua carga horária presencial reduzida e ainda precisam enviar formulário específico de ajuste e compensação de carga horária para a Secretaria de Gestão de Pessoas da UNIVASF, destacam os professores entrevistados. Assim, embora a EAD tenha passado a ocupar um espaço cada vez mais significativo no país, ainda é possível encontrar muita resistência e preconceito contra tal modalidade de ensino, vista, muitas vezes, como uma educação de qualidade inferior em razão das inúmeras iniciativas malsucedidas que marcaram o início da EaD no Brasil (CORRÊA; SANTOS, 2009). Os autores ainda ressaltam o fato de parte da comunidade acadêmica se sentir incomodada com os novos parâmetros de ensino, nos quais o centro da aprendizagem desloca-se do professor para o aluno.

Ainda existem resistência quando o quesito é Educação a Distância. Para aquelas pessoas de gerações onde a tecnologia faz parte do cotidiano comum, os esforços serão melhores aproveitados. Caso contrário, será mais uma tentativa frustrante porque não há ações motivacionais em paralelo para fomentar esse desejo.

Ent_UNIVASF_1 


\section{INFLUÊNCIA DA ESTRUTURA ORGANIZACIONAL-ADMINISTRATIVA DAS INSTITUIÇÕES DE ENSINO SUPERIOR NO DESENVOLVIMENTO DE COMPETÊNCIAS DOCENTES PARA ATUAÇÃO NA

De forma alguma. Um preconceito muito grande. Ainda não houve a absorção do que seria a EAD. Muita gente ainda entende a EAD como se fosse por correspondência, por correio. E que é uma função inferior. Não é considerado o coordenador. Você veja que as minhas horas trabalhadas não são computadas. Eu tenho que trabalhar extra. E ainda tenho que dar isso em formulário para a própria secretaria de gestão de pessoas. Eu não posso trabalhar no meu horário de trabalho. Então eu tenho que trabalhar 8 horas pela Univasf e mais 8 horas como coordenadora da EAD, eu trabalho de 12 a $16 \mathrm{~h}$ por dia porque sou coordenadora da EAD. Eu não concordo com isso. De jeito nenhum. É uma coordenação como outra qualquer. Como qualquer curso. Porque seria uma coordenação diferente?

Ent_UNIVASF_3

Não percebo. É uma cultura que vem enraizada desde mil novecentos e antigamente desde o instituto universal brasileiro. Criou-se essa cultura de que o curso não presta.

Ent_UNIVASF_8

Existe rejeição. Por incrível que pareça a gente encontra docentes... (...). Existe, pra muitos, ou para alguns professores ainda, aquela imagem de que EAD não é uma coisa que funciona, ela não atende a contento, é uma coisa meio que facilitada, existe ainda essa imagem. (...) Então, existem porque até os convites que a gente faz para alguns professores a gente encontra rejeição.

Ent_UNIVASF_10

O fato de os professores receberem bolsa para participar como docente nos cursos de educação a distância aparece tanto como um fator, que faz legitimar a EAD como um fator puramente financeiro para a participação do professor (ele participa porque sabe que é uma forma de aumentar o salário, considerando que seu regime é o de dedicação exclusiva e que não tem como exercer atividade remunerada fora a instituição, mas não porque acredita ou percebe a EAD como uma modalidade de ensino válida e institucionalmente reconhecida). Seguem as falas dos professores:

Existe um fator político aqui na universidade, pois o governo tem quebrado qualquer resistência com estratégia muito óbvia, que é pagando. Como nós não temos hora extra, como aumentar salário, então, alguns já disseram que é uma forma do governo cooptar os professores e diminuir essa resistência para massificação da distribuição de títulos por meio da EAD. Como? Dando bolsas. Ela é chamada de bolsa e não salário. Eu vejo gente que não acredita mas participa.

Ent_UNIVASF_7

Não (percebo aceitação). Minha percepção é bem mercadológica. Os professores estão engajados nesta proposta porque mesmo estando no quadro de dedicação exclusiva eles podem receber uma remuneração extra dentro da própria universidade.

Ent_UNIVASF_6

Embora até o fim de 2011, segundo Silva e Silva (2012), o patrimônio adquirido para a SEaD da UNIVASF tenha sido o de aproximadamente $\mathrm{R} \$ 900.000,00$ (novecentos mil reais), garantindo, assim, um investimento em infraestrutura (básica e tecnológica). A 
mudança na gestão da universidade provocou um impacto de adaptação aos novos membros, o que, de certa maneira, parece ter dificultado a completa legitimação da EAD na universidade.

\begin{abstract}
A EAD foi o centro de uma briga entre a gestão anterior e essa. Então, de certa forma, repercute ainda para que as pessoas ainda não se aproximem tanto dela, como tudo dentro da Univasf, o momento que é ou eles ou nós. Então, o grupo anterior estruturou a EAD, quando chega o novo grupo vai lá e desmonta a EAD toda. Então é um outro caminhar. (...) Então, por vezes você vê professor dizendo que não vai participar da EAD porque foi do outro, é coisa do Reitor. Não, isso não é coisa do Reitor. Isso é coisa da gestão atual, de uma política pública que está aí há dez anos. E aí as pessoas ainda ficam com esse ranço da eleição passada, da eleição futura, e deixam de legitimar uma ferramenta tão interessante como o ensino a distância.
\end{abstract}

Ent_UNIVASF_5

Com base nas análises de conteúdo dos documentos e das entrevistas realizadas, considerando o parâmetro de avaliação e os indicadores definidos a priori a partir da interpretação do modelo teórico escolhido para este estudo, foi possível estabelecer avaliações para os indicadores dessa dimensão, as quais podem ser observadas na tabela 2, a seguir:

Tabela 2 Avaliação dos indicadores da dimensão organizacional/administrativa.

\begin{tabular}{|c|c|c|c|c|c|c|}
\hline \multirow{2}{*}{ Dimensão } & \multirow{2}{*}{ Indicador(es) } & \multicolumn{5}{|c|}{ Conceitos } \\
\hline & & 1 & 2 & 3 & 4 & 5 \\
\hline \multirow{11}{*}{$\begin{array}{l}\text { Organizacional- } \\
\text { administrativa }\end{array}$} & 1. Infraestrutura básica & & & $\mathrm{x}$ & & \\
\hline & 2. Infraestrutura tecnológica & & & & & $\mathrm{x}$ \\
\hline & 3. $\quad$ Estruturas de apoio & $\mathrm{x}$ & & & & \\
\hline & 4. $\quad$ Adaptação das estruturas existentes & & $\mathrm{x}$ & & & \\
\hline & 5. Adaptação dos processos existentes & $\mathrm{x}$ & & & & \\
\hline & 6. $\quad$ Planejamento da implantação & $\mathrm{x}$ & & & & \\
\hline & 7. Gestão das partes interessadas (professores, alunos e técnicos) & $\mathrm{x}$ & & & & \\
\hline & 8. Gestão de qualidade & & & & & $\mathrm{x}$ \\
\hline & 9. $\quad$ Transparência nos processos de mudança & $\mathrm{x}$ & & & & \\
\hline & 10. Eficiência das estruturas & & $\mathrm{x}$ & & & \\
\hline & 11. Eficiência dos processos & & $\mathrm{x}$ & & & \\
\hline & Média & \multicolumn{5}{|c|}{2} \\
\hline
\end{tabular}

A dimensão organizacional/administrativa configura um quadro AQUÉM do que expressa o referencial mínimo de qualidade.

Fonte: elaboração dos autores (2015).

Assim, a partir do momento em que a dimensão organizacional-administrativa incide sobre o desenho organizacional e sobre as estruturas e processos (SEUFERT e EULER, 2004) e que há um forte componente político influenciador no posicionamento dos professores quanto à aceitação da EAD na UNIVASF, entende-se que parte da execução do planejamento da implantação da EAD, e, consequentemente, sua legitimação, ficaram comprometidos em função dos conflitos existentes entre a anterior e atual gestão da universidade, fazendo com 
que parte dos professores não aceite ingressar na EAD em razão de incompatibilidade de posicionamento político com a atual gestão.

O planejamento da UNIVASF, representado pelo PDI, contempla formalmente a capacitação do corpo docente para que seja possível implementar uma rede local de ensino superior a distância; no entanto, poucas ações no sentido de desenvolvimento de competências foram identificadas pelos professores entrevistados. Ações isoladas foram desenvolvidas na instituição, mas sem continuidade em virtude das mudanças políticas institucionais que ocorreram. Por essas razões, a UNIVASF encontra-se em uma situação aquém do que expressa o referencial mínimo de qualidade para a dimensão organizacional/administrativa.

\section{CONSIDERAÇÕES FINAIS}

Para responder à pergunta proposta, foi realizado um estudo qualitativo interpretativo básico, pois procurou-se as perspectivas das pessoas envolvidas em relação à influência da dimensão organizacional-administrativa no desenvolvimento de competências eletrônicas docentes. Os dados foram coletados por meio de entrevistas semiestruturadas, análise documental (Plano de Desenvolvimento Institucional 2009-2014; Plano de Capacitação da Secretaria de Gestão de Pessoas para os anos de 2009, 2010, 2011, 2012, 2013 e 2014; Plano Institucional de Formação Docente 2009-2013 e 2014-2017; e informações no site institucional) e material bibliográfico.

Do estudo da literatura conclui-se que, quando a profissão do professor passa a ser compreendida enquanto práticas associadas ao ato de ensinar, essa adquire características específicas (e distintas) de quaisquer outras atividades e/ou funções desempenhadas pelos professores do ensino superior, demandando, portanto, competências próprias e diferenciadas para tal. Ao se considerar, entretanto, o novo contexto educacional estabelecido pelo avanço tecnológico, pelo estímulo ao uso das TICs e pela consolidação da EAD, acredita-se ser de fundamental importância a consideração de competências tecnológicas no exercício da profissão docente. Nesse sentido, a competência eletrônica deve ser compreendida como uma competência para a ação específica de professores para dominar as tecnologias de aprendizagem. Sua aquisição requer mais do que aprender respectivamente novos conhecimentos, desenvolver novas competências ou a assumir novas atitudes.

Assim, os professores além de reforçarem as competências que já possuem, precisam, também, adquirir novas competências que lhes permitam conhecer e julgar por que, quando e 


\section{INFLUÊNCIA DA ESTRUTURA ORGANIZACIONAL-ADMINISTRATIVA DAS INSTITUIÇÕES DE ENSINO SUPERIOR NO DESENVOLVIMENTO DE COMPETÊNCIAS DOCENTES PARA ATUAÇÃO NA $E A D$ \\ DOI: http://dx.doi.org/10.5007/1983-4535.2016v9n2p1}

como utilizar as TIC na educação. Isso porque a EAD em muito difere no tempo e espaço da tradicional educação presencial, e o professor passa a ser um mediador ${ }^{2}$ no acesso à informação durante o processo de ensino-aprendizagem, exigindo novas competências docentes, uma vez que precisa ser sensibilizado e preparado para utilizar todo o potencial educativo das tecnologias disponíveis para a EAD e, assim, provavelmente, novos saberes deverão ser construídos.

Nesse sentido, faz-se necessário compreender que a dinâmica do processo ensinoaprendizagem, quando intermediada pelas TICs, difere quando comparada com a modalidade presencial, especialmente com relação aos papéis e às competências do professor e, também dos alunos, à nova realidade da sala de aula (que passa a ser virtual, interativa e tecnológica) e a um novo currículo no contexto de aprendizagem aberta. A eficiência desse processo (de ensino-aprendizagem) depende diretamente do ambiente de aprendizagem em que professores e alunos estão situados que, por sua vez, depende em grande parte do ajuste das competências dos docentes neste cenário.

Da pesquisa de campo tem-se que a implementação formal da EAD na instituição remete ao início de 2009 quando da adesão ao Sistema Universidade Aberta do Brasil (UAB). Diversos editais foram aprovados na Capes para aquisição de equipamentos e capacitação de profissionais para a EAD.

Dos professores respondentes do estudo tem-se um perfil bem definido. A maioria é do sexo masculino, com idade entre 31 e 36 anos, são docentes em regime de dedicação exclusiva com a instituição e estão em processo de capacitação (doutoramento), e com formação estritamente presencial.

Para a dimensão organizacional-administrativa os resultados da pesquisa mostram claramente que vários fatores dessa dimensão são importantes para o desenvolvimento das competências eletrônicas docentes. Embora esteja aquém do que expressa o referencial mínimo de qualidade para a educação a distância, tal dimensão pode influenciar positivamente o desenvolvimento das competências eletrônicas docentes para atuação na EAD. No PDI, há, em várias passagens do texto, a previsão ao estímulo e impulso da EAD, sugerindo haver um planejamento para implementação dessa modalidade de ensino na instituição (fator crucial

\footnotetext{
2 "Essa expressão [mediador], frequente nos discursos pedagógicos, caracteriza as abordagens que se opõem à escola tradicional e à de caráter espontaneista e se traduz didaticamente numa série de atitudes e procedimentos didáticos" (SOUZA; SARTORI; ROESLER, 2008, p.330).
} 
para o desenvolvimento das competências eletrônicas docentes segundo a literatura). Os professores entrevistados também reconhecem a importância do treinamento inicial que receberam (ainda que tenha sido apenas para operacionalização da plataforma), o que pode ter despertado nos docentes o desejo pelo desenvolvimento das competências eletrônicas. Questões políticas institucionais precisam ser superadas e a periodicidade do treinamento precisa existir para que a EAD possa se firmar na instituição.

\section{REFERÊNCIAS}

ARRUDA, Heloisa Paes de Barros. Entre o presencial e o virtual: a videoconferência, sentimentos e emoções implicados. In: BEHRENS, Marilda Aparecida; ENS, Romilda Teodora; VOSGERAU, Dilmeire Sant'Anna Ramos. Discutindo a educação na dimensão da práxis. Curitiba: Champagnat, 2007.

BANDEIRA-DE-MELLO, Rodrigo. Softwares em pesquisa qualitativa. In: GODOI, Christiane Kleinübing; BANDEIRA-DE-MELLO, Rodrigo; SILVA, Anielson Barbosa. Pesquisa qualitativa em estudos organizacionais: paradigmas, estratégias e métodos. São Paulo: Saraiva, 2006.

BARDIN, L. Análise de Conteúdo. São Paulo: Edições 70, 2011.

BAUER, Martin W.; AARTS, Bas. A construção do corpus: um princípio para coleta de dados qualitativos. In: BAUER, M. W.; GASKELL, G. Pesquisa qualitativa com texto imagem e som: um manual prático. Petrópolis: Vozes, 2002.

BAUER, Martin W.; GASKELL, George; ALLUM, Nicholas C. Qualidade, quantidade e interesses do conhecimento: evitando confissões. In: Bauer, Martin W.; Gaskell, George. Pesquisa qualitativa com texto, imagem e som: um manual prático. Petrópolis, RJ: Vozes, 2002.

BELLONI, Maria Luiza. Educação a distância. 5.ed. Campinas, SP: Autores Associados, 2009.

BERAZA, Miguel. A. Zalbaza. Uma nova didáctica para o ensino universitário: respondendo ao desafio do espaço europeu de ensino superior. Texto para Sessão Solene comemorativa do Dia da Universidade, por ocasião do $95^{\circ}$ aniversário da Universidade do Porto. Porto: Universidade do Porto, 2006.

BRASIL. Referenciais de qualidade para a modalidade de educação superior a distância. Brasília: MEC, 2007.

CAELLI, Kate; RAY, Lynne; MILL, Judy. Clear as Mud: Toward Greater Clarity in Generic Qualitative Research. International Journal of Qualitative Methods, v. 2, n. 2, p. 1-13, 2003. 
CASSUNDÉ, Fernanda Roda; CASSUNDÉ JUNIOR, Nildo. O estado do conhecimento sobre educação a distância (EAD) em Administração: por onde caminham os artigos? Fórum temático - oportunidades e desafios das práticas e da gestão de ensino de Administração a distância. Revista Gestão e Planejamento, Salvador, v. 13, n. 2, p. 366-380, maio/ago. 2012.

CHEN, Yu-Li. A mixed-method study of EFL teachers' Internet use in language instruction. Teaching and Teacher Education, v.24, p.1015-1028, 2008.

CORRÊA, Stevan de Camargo; SANTOS, Larissa Medeiros Marinho. Preconceito e educação a distância: atitudes de estudantes universitários sobre os cursos de graduação na modalidade a distância. ETD - Educação Temática Digital, Campinas, v.11, n.1, p.273-297, jul./ dez. 2009.

EHLERS, Ulf-Daniel; Schneckenberg, Dirk. Introduction: Changing Cultures in Higher Education. In: EHLERS, Ulf-Daniel; Schneckenberg, Dirk. Changing Cultures in Higher Education: Moving Ahead to Future Learning. New York: Springer International, 2010.

GODOY, Arilda Schmidt. Pesquisa qualitativa: tipos fundamentais. Revista de Administração de Empresas, São Paulo, v.35, n.3, p.20-29, Maio/Jun. 1995.

GILBERTO, Irene Jeanete Lemos. A educação a distância no ensino superior e a lógica das competências. Revista Gestão Universitária na América Latina, v.6, n.1, p.273-286, jan. 2013.

GODOI, Christiane Kleinübing; MATTOS, Pedro Lincoln Carneiro Leão. Entrevista qualitativa: instrumento de pesquisa e evento dialógico. In: GODOI, Christiane Kleinübing; BANDEIRA-DE-MELLO, Rodrigo; SILVA, Anielson Barbosa. Pesquisa qualitativa em estudos organizacionais: paradigmas, estratégias e métodos. São Paulo: Saraiva, 2006.

GODOY, Arilda Schmidt. Refletindo sobre critérios de qualidade da pesquisa qualitativa. Gestão.Org, v.3, n.2, mai./ago. 2005.

HARRY, K.; DESMONDD, K.; JOHN, M. H. Distance education: new perspectives. Routledge Studies in distance education. New York, NY: Routledge, 2006.

ISMAN, Aytekin; ALTINAY, Zehra; ALTINAY, Fahriye. Roles of the students and teachers in distance education. Turkish online Journal of Distance Education, v.5, n.4, October, 2004.

Jakobsdóttir, Sólveig; McKeown, Lindy; HOVEN, Debra. Using the new information and communication technologies for the continuing professional development of teachers through open and distance learning. In: DANAHER, Patrick Alan; UMAR, Abdurrahman. Teacher education through open and distance learning. Vancouver: Commonwealth learning, 2010. 
LATCHEN, Colin. Using ICT to train teachers in ICT. In: DANAHER, Patrick Alan; UMAR, Abdurrahman. Teacher education through open and distance learning. Vancouver: Commonwealth learning, 2010.

Lwoga, Edda. Making learning and Web 2.0 technologies work for higher learning institutions in Africa. Campus-Wide Information Systems, v. 29, n.2, p. 90-107, 2012.

MAIETTA, Raymond C. Computer-assisted data analysis. In: GIVEN, Lisa M. The Sage Encyclopedia os Qualitative Research Methods. California: SAGE Publications, 2008.

MARTINS, Onilza Borges. Os caminhos da EAD no Brasil. Revista Diálogo Educacional, Curitiba, v.8, n.24, p.357-371, maio/ago. 2008.

MENDONÇA, José Ricardo Costa; PAIVA, Kely César Martins; PADILHA, Maria Auxiliadora; BARBOSA, Milka Alves Correia; MARTINS, Marco Antônio Buarque.

Competências Eletrônicas de Professores para Educação a Distância no Ensino Superior no Brasil: discussão e proposição de modelo de análise. In: 2. ${ }^{a}$ Conferência do FORGES Fórum da Gestão do Ensino Superior nos Países e Regiões de Língua Portuguesa, 2012, Macau, China. Por um Ensino Superior de Qualidade nos Países e Regiões de Língua Portuguesa, 2012b.

MENEZES, Luis Carlos. Universidade sitiada: A ameaça de liquidação da universidade brasileira. São Paulo: Fundação Perseu Abramo, 2001.

MERRIAM, Sharan B. Qualitative Research and Case Study Applications in Education. San Francisco: Jossey-Bass, 1998.

Qualitative research in practice: examples for discussion and analysis. San Francisco: Jossey-Bass, 2002.

MOORE, Michael; KEARSLEY, Greg. Educação a distância: uma visão integrada. São Paulo: Cengage Learning, 2011.

MOZATTO, A. R.; GRZYBOVSKI, D. Análise de Conteúdo como Técnica de Análise de Dados Qualitativos no Campo da Administração: Potencial e Desafios. Revista de Administração Contemporânea, v. 15, n. 4, p. 731-747, 2011.

Oguzor, Nkasiobi Silas; Opara, Jacinta Agbarachi. Media technology and vocational education in Nigeria: Problems and prospects. Applied Technologies \& Innovations, v.4, n.1, p.39-47, april 2011.

PADILHA, Maria Auxiliadora Soares; HELAL, Diogo Henrique; MENDONÇA, José Ricardo Costa. Educação a distância em Administração: olhares sobre as pesquisas, vivências e perspectivas. Fórum temático - oportunidades e desafios das práticas e da gestão de ensino de Administração a distância. Revista Gestão e Planejamento, Salvador, v. 13, n. 2, p. 356365, maio/ago. 2012. 
PAIVA, Kely Cesar Martins. Gestão de competências e a profissão docente: um estudo em universidades no estado de Minas Gerais. 2007. Tese (Doutorado) - Programa de Pós-

Graduação em Administração, Universidade Federal de Minas Gerais, Belo Horizonte, 2007.

RAMA, Claudio. Tipología de las tendencias de la virtualización de la educación superior en América Latina. Revista Diálogo Educacional, Curitiba, v.8, n.24, p.341-355, maio/ago. 2008.

RAMOS, Marise Nogueira. A pedagogia das competências: autonomia ou adaptação? São Paulo: Cortez, 2002.

SANAVRIA, Claudio Zarate. Avaliação da aprendizagem à distância: concepções e práticas de professores no ensino superior. 2008. Dissertação (Mestrado) - Programa de PósGraduação em Educação, Universidade Católica Dom Bosco, Campo Grande, 2008.

Sánchez-Franco, Manuel J.; Martínez-López, Francisco J.; Martín-Velicia, Félix A. Exploring the impact of individualism and uncertainty avoidance in Web-based electronic learning: An empirical analysis in European higher education. Computers \& Education, v.52, p.588-598, 2009.

SCHNECKENBERG, Dirk. eCompetence Development Measures for Faculty in Higher Education - A Comparative International Investigation. Tese. Fachbereich

Bildungswissenschaften der Universität Duisburg-Essen. Standort Essen, 2007.

. El e-learning transforma la educación superior. Educar, n.33, p.143-156, 2004.

Face the Human Factor: The Role of eCompetence in the Future of Higher

Education. In: NUNES, M.B.; McPHERSON, M. International Association for

Development of the Information Society: Multi-Conference on Computer Science and Information Systems, 22-27 July, p.98-105, 2008a.

No Future Learning without Present Staff: The Role of Faculty in University Innovation. Proceedings of eLearning Forum, $2008 \mathrm{~b}$.

. Overcoming barriers for eLearning in universities: portfolio models for eCompetence development of faculty. British Journal of Educational Technology, v.41, n.6, p.979-991, 2010a.

What is e-Competence? Conceptual Framework and Implications for Faculty Engagement. In: EHLERS, Ulf-Daniel; Schneckenberg, Dirk. Changing Cultures in Higher Education: Moving Ahead to Future Learning. New York: Springer International, 2010b.

Schneckenberg, Dirk; Wildt, Johannes. Understanding the concept of ecompetence for academic staff. In: Labhrainn, Mac; LEGG, McDonald; Schneckenberg, Dirk; WILDT, Johannes. The Challenge of eCompetence in Academic Staff Development. Galway: CELT, 2006. 
Schönwald, Ingrid. Sustainable implementation of e-learning as a change process at universities. St. Gallen, Switzerland: Swiss Centre for Innovations in Learning, 2003.

SEUFERT, Sabine; EULER, Dieter. Nachhaltigkeit von eLearning-Innovationen: Ergebnisse einer Expertenbefragung. Arbeitsbericht 1 des Swiss Center for Innovations in Learning St. Gallen: Institut für Wirtschaftspädagogik, Juni 2003.

Nachhaltigkeit von eLearning-Innovationen: Ergebnisse einer Delphi-studie. Arbeitsbericht 2 des Swiss Center for Innovations in Learning St. Gallen: Institut für Wirtschaftspädagogik, Januar 2004.

SILVA, João Carlos Sedraz; SILVA, Luciano Gomes. Implantação e institucionalização da EAD na UNIVASF. In: Congresso Brasileiro de Ensino Superior a Distância, 2012, Recife/PE. Anais...Congresso Brasileiro de Ensino Superior a Distância, 2012.

SILVA, Maria Aparecida; LIMA FILHO, Dario de Oliveira; RIBEIRO, Silvar; CASTANHA, Anderson. Projeto Pedagógico do curso de Especialização em Gestão Pública. MEC: Brasil, 2012.

SOUZA, Alba Regina Battisti; SARTORI, Ademilde Silveira; ROESLER, Jucimara. Mediação pedagógica na educação a distância: entre enunciados teóricos e práticas construídas. Revista Diálogo Educacional, Curitiba, v.8, n.24, p.327-339, maio/ago. 2008.

STAKE, Robert E. Qualitative case studies. In: DENZIN, Norman K.; LINCOLN, Yonna S. Handbook of qualitative research. 3rd. ed. California: Sage Publications, 2005.

TIGELLAR, Dineke E. H.; DOLMANS, Diana H. J. M.; WOLFHAGE, Ineke H. A. P.; VAN DER VLEUTEN, Cees p. M. The development and validation of a framework for teaching competencies in higher education. Higher education, 48, p.253-268, 2004.

TORRES, Patrícia Lupion; MARRIOTT, Rita de Cássia Veiga; MATOS, Elizete Lúcia Moreira. Mediação pedagógica com o uso de mapas conceituais em ambiente virtual de aprendizagem. In: ENS, Romilda Teodora; BEHRENS, Marilda Aparecida; VOSGERAU, Dilmeire Sant'Anna Ramos. Trabalho do professor no espaço escolar. Curitiba: Champagnat, 2009.

UMAR, Abdurrahman; DANAHER, Patrick Alan. Setting the scene for interrogating teacher education through open and distance learning. In: DANAHER, Patrick Alan; UMAR, Abdurrahman. Teacher education through open and distance learning. Vancouver: Commonwealth learning, 2010.

VIEIRA, Marcelo Milano Falcão. Por uma Boa Pesquisa (Qualitativa) em Administração. In: VIEIRA, M Marcelo Milano Falcão; ZOUAIN, Moraes Zouain. Pesquisa Qualitativa em Administração. Rio de Janeiro: FGV, 2004. 
VOLK, Benno; KELLER, Stefan Andreas. The «Zurich E-Learning Certificate» A role model for the acquirement of eCompetence for Academic Staff and an example of a practical implementation. European Journal of Open, Distance and E-Learning, p.1-8, 2010.

Wheeler, Steve. Open Content, Open Learning 2.0: Using Wikis and Blogs in Higher Education. In: EHLERS, Ulf-Daniel; Schneckenberg, Dirk. Changing Cultures in Higher Education: Moving Ahead to Future Learning. New York: Springer International, 2010.

ZANOTELLI, Reivani Chisté. Professores do ensino superior frente às novas tecnologias: usos e desusos do Computador e da Internet no cotidiano de trabalho. 2009. Tese (Doutorado) - Programa de Pós-Graduação em Psicologia Clínica, Pontifícia Universidade Católica do Rio de Janeiro, Rio de Janeiro, 2009. 